\title{
Desafios do mercado brasileiro de dispositivos médicos e sua relação com o aumento de gastos de saúde no país
}

\author{
Challenges of the Brazilian medical device market and its relation to
} the increase of health expenses in the country

Desafíos del mercado brasileño de dispositivos médicos y su relación con el aumento de los costos de atención médica

Thais SEILER(1)

Tarsila Teixeira Vilhena LOPES ${ }^{(1)}$ Brunna Verna Castro GONDINHO(2)

Felipe Galvão MACHADO ${ }^{(1)}$ Jaqueline Vilela BULGARELI ${ }^{(3)}$

Recebido: 02 out 2019 Revisado: $17 \mathrm{dez} .2019$ Aceito: 16 jan 2020

Autor de correspondência: Brunna Verna Castro Gondinho brunnaverna@phb.uespi.br

Conflito de interesses: Os autores declaram não haver nenhum interesse profissional ou pessoal que possa gerar conflito de interesses em relação a este manuscrito.

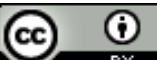

\footnotetext{
(1)Universidade de São Paulo - USP, São Paulo, SP, Brasil.

${ }^{(2)}$ Faculdade de Odontologia e Enfermagem - FACOE, Universidade Estadual do Piauí - UESPI, Parnaíba, PI, Brasil.

(3)Faculdade de Odontologia, Universidade de Uberlândia - UFU, Minas Gerais, MG, Brasil.
}

\section{Resumo}

A expansão de dispositivos médicos vem afetando o modo de financiamento da área da saúde. Este artigo fez uma revisão na literatura sobre estudos que abordaram sobre essa relação entre o mercado de dispositivos médicos e o aumento de gasto de saúde. Tentou compreender as imperfeições desse mercado, como também a variação de preços e a necessidade de regulação desses dispositivos no Brasil e em algumas experiências no mundo. Tratou-se de uma revisão integrativa de literatura, em que foram selecionados os artigos relacionados com o tema. A análise transcorreu com o total de 21 artigos. Dentre eles, foi possível mensurar artigos que retrataram sobre a imperfeição do mercado de dispositivos médicos; referiram sobre as regulações; mencionaram sobre a legislação e transparência no custo-efetividade e abordaram sobre a transparência de preços. Além disso, foi possível observar que majoritariamente os autores apontaram argumentos favoráveis à regulação de precificação e sobre a transparência desses processos regulatórios. O mercado de dispositivos médicos apresenta uma diversidade de dispositivos que torna complexa a prática regulatória. A transparência e responsabilidade são práticas recomendadas para minimizar os efeitos provocados pela disfuncionalidade do mercado de produtos de saúde.

Descritores: Equipamentos e Provisões; Regulação e Fiscalização em Saúde; Honorários e Preços; Setor de Assistência à Saúde; Transparência dos Gastos. 


\begin{abstract}
The expansion of medical devices has been affecting the way healthcare is financed. This article has reviewed the literature on studies that addressed this relationship between the medical device market and increased healthcare spending. It tried to understand the imperfections of this market, as well as the price variation and the need for regulation of these devices in Brazil and in some experiences in the world. This was an integrative literature review, in which articles related to the theme were selected. The analysis was performed with a total of 21 articles. Among them, it was possible to measure articles that portrayed the imperfection of the medical device market; referred to the regulations; mentioned legislation and transparency on cost-effectiveness and addressed price transparency. In addition, it was observed that the majority of the authors pointed arguments in favor of pricing regulation and about the transparency of these regulatory processes. The medical device market has a variety of devices that makes regulatory practice complex. Transparency and accountability are best practices to minimize the effects of the dysfunctionality of the healthcare product market.
\end{abstract}

Keywords: Equipment and Supplies; Health Care Coordination and Monitoring; Fees and Charges; Health Care Sector; Cost Transparency.

\title{
Resumen
}

La expansión de los dispositivos médicos ha estado afectando la forma en que se financia la atención médica. Este artículo revisó la literatura sobre estudios que abordaron esta relación entre el mercado de dispositivos médicos y el aumento del gasto en atención médica. Intentó comprender las imperfecciones de este mercado, así como la variación de precios y la necesidad de regulación de estos dispositivos en Brasil y en algunas experiencias en el mundo. Esta fue una revisión integradora de la literatura, en la que se seleccionaron artículos relacionados con el tema. El análisis se realizó con un total de 21 artículos. Entre ellos, fue posible medir artículos que retrataban sobre la imperfección del mercado de dispositivos médicos; referido a las regulaciones; mencionaron la legislación y la transparencia de la rentabilidad y abordaron la transparencia de los precios. Además, se observó que la mayoría de los autores señalaron argumentos a favor de la regulación de precios y sobre la transparencia de estos procesos regulatorios. El mercado de dispositivos médicos tiene una variedad de dispositivos que hace que la práctica regulatoria sea compleja. La transparencia y la rendición de cuentas son las mejores prácticas para minimizar los efectos de la disfuncionalidad del mercado de productos de salud.

Palabras-claves: Equipos y Suministros; Regulación y Fiscalización en Salud; Honorarios y Precios Sector de Atención de Salud; Transparencia de los gastos.

\section{Introdução}

Os dispositivos médicos têm tido uma preocupação diária para o setor da saúde. Isso porque o uso desses recursos tecnológicos traduz em melhoria da qualidade de vida da população. Contudo, a demanda por cada vez mais aparatos tecnológicos reflete diretamente no aumento dos investimentos financeiros na área, sendo uma questão de destaque a ser enfrentada pelos gestores ao redor do mundo. ${ }^{1}$

Existem inúmeras formas de apresentação desses dispositivos médicos, também conhecidos como produtos para a saúde, tais como: equipamentos, aparelho, instrumento, material, artigo, sistema de uso ou aplicação médica, odontológica ou laboratorial, 
incluindo software para fins de diagnósticos ou terapêuticos. São meios auxiliares com efeito em seres humanos, destinados à prevenção, diagnóstico, tratamento, reabilitação ou atenuação de uma doença ou de uma deficiência. Estima-se, pela Organização Mundial de Saúde, que existam mais de 1.5 milhão de dispositivos médicos em circulação no mundo, sendo no Brasil uma média de 14.000 novos produtos lançados por ano. Em 2016, por exemplo, foram registrados 1.594 dispositivos médicos no Brasil, sendo 400 relacionados com materiais ortopédicos. ${ }^{1-3}$

O consumo no país por dispositivos médicos cresceu 3,4\% no primeiro trimestre de 2018, em relação ao período de 2017. As importações totais dos dispositivos médicos, contabilizados de janeiro a março, totalizaram o montante de US\$2,4 bilhões, com um crescimento de 5,9\% no mesmo período de 2017.4 Esse aumento na demanda desses dispositivos faz com que haja uma ampliação na presença de grandes companhias que atuam no setor em países em desenvolvimento. O setor produtivo de dispositivos médicos brasileiros ainda é discreto, em face do mercado mundial. Ainda assim, em determinados segmentos de alta tecnologia, há empresas de dispositivos médicos no Brasil que obtiveram êxito, com boa relação custo-efetividade, adequados às necessidades de saúde e com elevado potencial para exportação. Uma das razões que o autor sugere para justificar a ampliação do uso dessas tecnologias é pelas mudanças demográficas e epidemiológicas do Brasil (aumento de idosos) e também sociais, como pelos traumas por violência urbana e acidentes de trânsito. ${ }^{3}$

Diante do cenário supracitado, há uma preocupação dos gestores das políticas do governo no que se refere à regulação desses dispositivos médicos. As Ciências Econômicas apontam alguns desafios frente à regulação desse mercado. São elas: condutas de agentes econômicos; fiscalização, monitoramento e controle sanitário; fatores culturais; diversidade de produtos no mercado brasileiro; transparência das informações sobre os atributos de qualidade dos produtos; existência de barreiras à entrada de novas empresas; formação de monopólio/oligopólio em determinados nichos de mercado. Nesse sentido, falhas nessa regulação implicam em resultados ineficientes ou socialmente indesejáveis, impactando na eficiência econômica e no bem-estar social. ${ }^{3}$

Considerando que, o uso dos dispositivos médicos representa um protagonismo no setor da saúde e um interesse econômico do Estado frente aos novos mercados. Esse estudo procurou revisar na literatura as produções científicas que abordaram sobre o mercado dos dispositivos médicos, procurando entender as variações de preços, como também a necessidade de regulação desse mercado no Brasil.

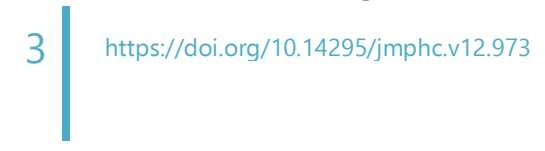




\section{Metodologia}

Esta pesquisa se dedicou a realizar uma revisão integrativa de estudos prévios cujos temas se relacionassem com a regulação e precificação de dispositivos médicos. A revisão integrativa permite a formulação de uma síntese do conhecimento sobre um determinado assunto, sendo um método frequentemente usado nas áreas da saúde. Consiste em um método que se propõe a trazer uma análise ampla da literatura sobre o objeto escolhido, com discussões sobre métodos e resultados de pesquisas, assim como reflexões sobre a realização de futuros estudos. Uma das vantagens desse método de revisão comparado aos demais é que ele permite a combinação de dados teóricos e empíricos. ${ }^{5}$

O desenvolvimento de uma revisão narrativa requer do revisor se orientar por algumas etapas: identificação do tema e seleção da hipótese ou questão de pesquisa para a elaboração da revisão integrativa; estabelecimento de critérios para inclusão e exclusão de estudos/amostragem ou busca na literatura; definição das informações a serem extraídas dos estudos selecionados/categorização dos estudos; avaliação dos estudos incluídos na revisão integrativa; interpretação dos resultados e apresentação da revisão/síntese do conhecimento. ${ }^{5}$ A partir dessas etapas que esta pesquisa de desenvolveu.

Primeiramente, delimitou-se o tema que consistiu em compreender os desafios do mercado brasileiro de dispositivos médicos e sua relação com o aumento de gastos de saúde no país. Na sequência, estabeleceram-se os critérios de inclusão e exclusão. Uma parte essencial para identificar os artigos para posterior análise e interpretação. Constituíramse os critérios de inclusão os artigos que continham alguns dos descritores previamente selecionados; artigos publicados em português, inglês, espanhol; artigos na íntegra; publicações relacionadas com a temática definida. Àqueles que, porventura, não se enquadravam nesses critérios supracitados foram descartados, sendo este o critério de exclusão dessa revisão. Vale ressaltar que não foram excluídos trabalhos científicos em formatos de revisão, monografias, teses e dissertações. Com relação ao recorte temporal, não foi estabelecido um período determinado, exceto no site do "Google Scholar" que se restringiram os estudos que estivessem dentro do período de agosto de 2015 a março de 2019.

As bases de dados dos periódicos científicos utilizadas para a seleção dos artigos foram PubMed e Scopus. Outras fontes utilizadas foram o site de busca "Google Scholar" e também relatórios governamentais do Brasil. Sendo os descritores cadastrados no Descritores em Ciências da Saúde - DeCS: dispositivos médicos, regulação, preços, 
mercado ou no 'Medical Subject Headings - MeSH: equipment and supplies, Medical Devices, Regulation; Social Control; equipment. As estratégias de busca se fundamentaram pela combinação dos operadores boolianos $A N D$ e $O R$. Optou-se por filtrar os artigos no Google Scholar por descritores específicos, foram eles: dispositivos médicos, dispositivos médicos implantáveis, regulação, preços, Agência Nacional de Vigilância Sanitária - ANVISA, conforme o recorte temporal previamente mencionado. Com relação aos relatórios governamentais, a busca foi realizada por um questionamento por e-mail a expertises da área da saúde.

A terceira etapa dessa revisão teve por objetivo organizar e sumarizar as informações que devem estar contidas na amostra dessa pesquisa. Equivale à etapa de coleta de dados para definir quais informações foram extraídas para responder à problemática em questão. Feito isso, foi realizado uma análise crítica dos estudos selecionados, almejando determinar as concordâncias e as divergências das publicações encontradas. A partir dessa análise, os dados foram interpretados e discutidos, com o propósito de ser construído um novo conhecimento. ${ }^{5}$ Essa sistematização foi descrita nos resultados e discussão.

\section{Resultados}

A amostra inicial dos artigos selecionados constituiu-se por 140 publicações, em que cinco estavam duplicadas, logo foi possível obter o total de 135. Contudo, após a análise prévia deste material foi selecionado aqueles que atendiam aos critérios de elegibilidade, o resultado final correspondeu a 21 artigos. Sendo 52\% da base Pubmed $(n=11), 24 \%$ referentes aos Relatórios Governamentais (Brasil) $(n=5), 14 \%$ do site Google $\operatorname{Scholar}(\mathrm{n}=3)$ e $10 \%$ da base Scopus $(\mathrm{n}=2)$.

Destes 21 estudos científicos, foi possível dividi-los conforme sua localidade. Assim, foram encontrados sete dos Estados Unidos, sete do Brasil, três da Inglaterra, dois da França, um de Portugal e um da Bélgica, conforme apresentado na Quadro 1. 
Quadro 1- Principais características dos estudos incluídos. São Paulo, SP, Brasil, 2003-2019.

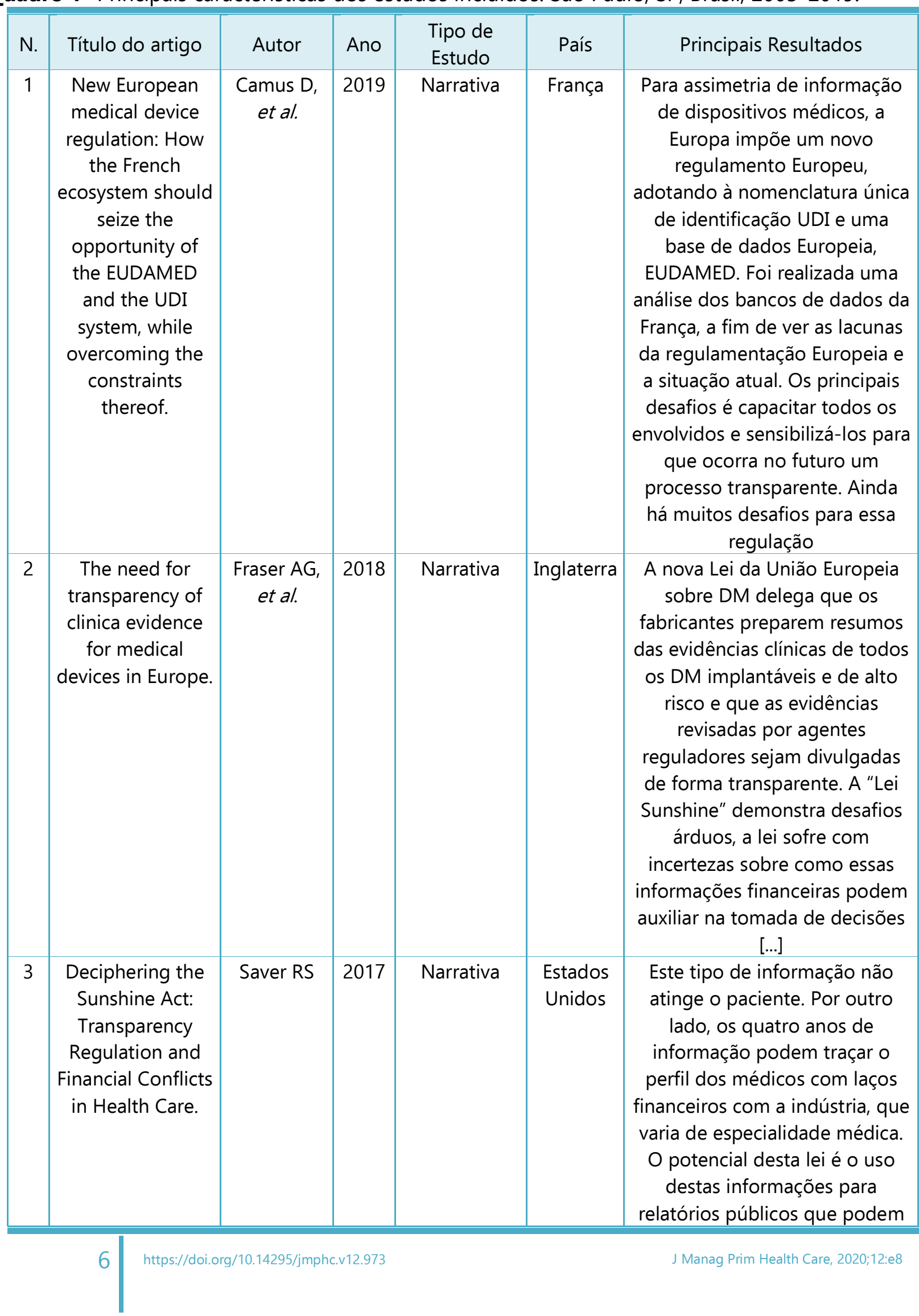


ISSN 2179-6750

\begin{tabular}{|c|c|c|c|c|c|c|}
\hline N. & Título do artigo & Autor & Ano & $\begin{array}{l}\text { Tipo de } \\
\text { Estudo }\end{array}$ & País & Principais Resultados \\
\hline & & & & & & $\begin{array}{l}\text { ser utilizados pelos reguladores, } \\
\text { advogados e formuladores de } \\
\text { políticas para examinarem mais } \\
\text { de perto as prescrições e } \\
\text { encaminhamentos médicos. }\end{array}$ \\
\hline 4 & $\begin{array}{l}\text { Life cycle of } \\
\text { medical product } \\
\text { rules issued by } \\
\text { the US Food and } \\
\text { Drug } \\
\text { Administration. }\end{array}$ & $\begin{array}{c}\text { Hwang TJ, } \\
\text { et al. }\end{array}$ & 2014 & Exploratório & $\begin{array}{l}\text { Estados } \\
\text { Unidos }\end{array}$ & $\begin{array}{l}\text { O FDA abre oportunidades para } \\
\text { diversas partes interessadas a } \\
\text { participarem e influenciarem no } \\
\text { processo de escrita e criação } \\
\text { das regras de regulação de } \\
\text { dispositivos médicos, com isso } \\
\text { há grandes divergências de } \\
\text { opiniões, consequentemente o } \\
\text { tempo de análise acaba sendo } \\
\text { longo. Sugerem uma reforma } \\
\text { na transparência e eficiência } \\
\text { das requlações. }\end{array}$ \\
\hline 5 & $\begin{array}{l}\text { Special funding } \\
\text { schemes for } \\
\text { innovative } \\
\text { medical devices } \\
\text { in French } \\
\text { hospitals: the } \\
\text { pros and cons of } \\
\text { two different } \\
\text { approaches. }\end{array}$ & $\begin{array}{l}\text { Martelli N, } \\
\text { et al. }\end{array}$ & 2014 & Exploratório & França & $\begin{array}{l}\text { Os dispositivos médicos } \\
\text { quando lançados no mercado } \\
\text { europeu, tem pouca evidência } \\
\text { clínica sobre sua segurança e } \\
\text { eficácia, por estarem em fase } \\
\text { inicial de desenvolvimento e } \\
\text { pelas falhas do sistema europeu } \\
\text { de regulação. Vários países } \\
\text { Europeus criaram esquemas de } \\
\text { reembolso temporário, assim } \\
\text { conseguem monitorar a eficácia } \\
\text { dos dispositivos médicos. A } \\
\text { França usa dois tipos de } \\
\text { abordagem para coletar os } \\
\text { dados: cobertura com } \\
\text { desenvolvimento de evidência } \\
\text { que é apoiada pelo Artigo 165- } \\
\text { 1-1 e programas nacionais de } \\
\text { pesquisa. Entre os prós e } \\
\text { contras de ambas de ambas as } \\
\text { políticas de cobertura com } \\
\text { desenvolvimento de evidência } \\
\text { da Alemanha e Reino Unido, } \\
\text { sugerem limitações comuns e } \\
\text { necessitam de transparência, } \\
\text { aprimoramento e um trabalho } \\
\text { conjunto com fabricantes, }\end{array}$ \\
\hline
\end{tabular}


ISSN 2179-6750

\begin{tabular}{|c|c|c|c|c|c|c|}
\hline N. & Título do artigo & Autor & Ano & $\begin{array}{l}\text { Tipo de } \\
\text { Estudo }\end{array}$ & País & Principais Resultados \\
\hline & & & & & & $\begin{array}{c}\text { autoridades de saúde e } \\
\text { hospitais para tornar as } \\
\text { políticas operacionais. }\end{array}$ \\
\hline 6 & $\begin{array}{l}\text { Improving } \\
\text { medical device } \\
\text { regulation: the } \\
\text { United States and } \\
\text { Europe in } \\
\text { perspective. }\end{array}$ & $\begin{array}{c}\text { Sorenson } \\
\text { C, et al. }\end{array}$ & 2014 & Exploratório & Inglaterra & $\begin{array}{l}\text { Comparando o sistema } \\
\text { regulamentação dos Estados } \\
\text { Unidos e Europa, eles se } \\
\text { diferem nos quesitos de } \\
\text { orientação, mandato, requisitos, } \\
\text { evidências de pré e pós- } \\
\text { mercado e transparência de } \\
\text { processo. Ambos os sistemas } \\
\text { enfrentam desafios } \\
\text { semelhantes, como a segurança } \\
\text { e eficácia dos dispositivos } \\
\text { médicos, para isso estão sendo } \\
\text { revistas e analisadas } \\
\text { regulamentações de pós- } \\
\text { comercialização como forma de } \\
\text { rastrear e monitorar esses } \\
\text { dispositivos médicos a fim de } \\
\text { assegurar e aprimorar a saúde } \\
\text { pública. }\end{array}$ \\
\hline 7 & $\begin{array}{l}\text { How does } \\
\text { medical device } \\
\text { regulation } \\
\text { perform in the } \\
\text { United States and } \\
\text { the European } \\
\text { union? A } \\
\text { systematic review. }\end{array}$ & $\begin{array}{c}\text { Kramer DB, } \\
\text { et al. }\end{array}$ & 2012 & $\begin{array}{c}\text { Revisão } \\
\text { Sistemática }\end{array}$ & $\begin{array}{l}\text { Estados } \\
\text { Unidos }\end{array}$ & $\begin{array}{l}\text { Encontrados estudos de } \\
\text { avaliação e tempo de pré- } \\
\text { comercialização }(n=9) \text {, estudos } \\
\text { de recalls de dispositivos ( } n= \\
\text { 8) e pesquisas com fabricantes } \\
\text { de dispositivos }(n=3 \text { ). Esses } \\
\text { estudos fornecem evidências de } \\
\text { problemas de qualidade em } \\
\text { envios pré-mercado nos EUA, } \\
\text { fornecem visões conflitantes da } \\
\text { segurança de dispositivos com } \\
\text { base principalmente em dados } \\
\text { de recall e transmitem } \\
\text { percepções de alguns líderes } \\
\text { do setor de auto pesquisas. }\end{array}$ \\
\hline 8 & $\begin{array}{l}\text { The need for } \\
\text { greater price } \\
\text { transparency in }\end{array}$ & $\begin{array}{c}\text { Hahn RW, } \\
\text { et al. }\end{array}$ & 2008 & $\begin{array}{c}\text { Revisão } \\
\text { Narrativa }\end{array}$ & $\begin{array}{l}\text { Estados } \\
\text { Unidos }\end{array}$ & $\begin{array}{l}\text { A divulgação obrigatória de } \\
\text { preços pode gerar benefícios e } \\
\text { também custos adicionais. Não }\end{array}$ \\
\hline
\end{tabular}


ISSN 2179-6750

\begin{tabular}{|c|c|c|c|c|c|c|}
\hline N. & Título do artigo & Autor & Ano & $\begin{array}{l}\text { Tipo de } \\
\text { Estudo }\end{array}$ & País & Principais Resultados \\
\hline & $\begin{array}{l}\text { the medical } \\
\text { device industry: } \\
\text { an economic } \\
\text { analysis. }\end{array}$ & & & & & $\begin{array}{l}\text { acreditam que a } \\
\text { obrigatoriedade de preços de } \\
\text { dispositivos médicos possa ser } \\
\text { aprovada em um teste de } \\
\text { custo-benefício. }\end{array}$ \\
\hline 9 & $\begin{array}{l}\text { Price } \\
\text { transparency for } \\
\text { medical devices. }\end{array}$ & $\begin{array}{c}\text { Pauly MV, } \\
\text { et al. }\end{array}$ & 2008 & $\begin{array}{c}\text { Revisão } \\
\text { Narrativa }\end{array}$ & $\begin{array}{l}\text { Estados } \\
\text { Unidos }\end{array}$ & $\begin{array}{l}\text { Há disparidade de valores entre } \\
\text { os hospitais americanos devido } \\
\text { ao sigilo na divulgação de } \\
\text { valores. A divulgação de preços } \\
\text { proposta pela legislação pode } \\
\text { acelerar uma reestruturação e } \\
\text { melhorar a negociação dos } \\
\text { hospitais. }\end{array}$ \\
\hline 10 & $\begin{array}{l}\text { Health economics } \\
\text { of medical } \\
\text { devices: } \\
\text { opportunities and } \\
\text { challenges. }\end{array}$ & Simoens S & 2008 & $\begin{array}{c}\text { Revisão } \\
\text { Narrativa }\end{array}$ & Bélgica & $\begin{array}{l}\text { O mercado de dispositivos } \\
\text { médicos tende a ser } \\
\text { fragmentado, carecem de } \\
\text { transparência e concorrência. } \\
\text { Muitos países desenvolvidos } \\
\text { têm buscado métodos para } \\
\text { baixar os preços, restringir } \\
\text { reembolso público } \\
\text { desnecessário e promover o } \\
\text { uso eficiente das tecnologias } \\
\text { em saúde. Há a necessidade de } \\
\text { realizar avaliações de custo- } \\
\text { efetividade dos dispositivos } \\
\text { médicos e implementar } \\
\text { estruturas que avaliem novos } \\
\text { dispositivos médicos para } \\
\text { implementação e tomada de } \\
\text { decisões de preços e } \\
\text { reembolso. }\end{array}$ \\
\hline 11 & $\begin{array}{l}\text { Regulating the } \\
\text { economic } \\
\text { evaluation of } \\
\text { pharmaceuticals } \\
\text { and medical } \\
\text { devices: a } \\
\text { European } \\
\text { perspective }\end{array}$ & $\begin{array}{c}\text { Cookson } \mathrm{R}, \\
\text { et al. }\end{array}$ & 2003 & $\begin{array}{c}\text { Revisão } \\
\text { Narrativa }\end{array}$ & Inglaterra & $\begin{array}{l}\text { A uma grande preocupação na } \\
\text { Europa referente à evidência } \\
\text { econômica, transparência e } \\
\text { prestação de contas dos } \\
\text { reembolsos públicos de } \\
\text { dispositivos médicos. Sendo } \\
\text { estes: desafios de publicarem } \\
\text { todas as evidências econômicas } \\
\text { usadas nas decisões de } \\
\text { reembolso; revisão de leis de } \\
\text { dados econômicos pertinentes } \\
\text { a dispositivos médicos novos }\end{array}$ \\
\hline
\end{tabular}


ISSN 2179-6750

\begin{tabular}{|c|c|c|c|c|c|c|}
\hline N. & Título do artigo & Autor & Ano & $\begin{array}{l}\text { Tipo de } \\
\text { Estudo }\end{array}$ & País & Principais Resultados \\
\hline & & & & & & $\begin{array}{l}\text { lançados no mercado; melhor } \\
\text { embasamento de metodologias } \\
\text { de avaliação econômica; } \\
\text { negociar a revisão de preços } \\
\text { pós-lançamento dos } \\
\text { dispositivos médicos, depois } \\
\text { que estes já estão consolidados } \\
\text { no mercado e com informações } \\
\text { suficientes sobre sua eficácia. }\end{array}$ \\
\hline 12 & $\begin{array}{l}\text { Evolving } \\
\text { reimbursement } \\
\text { and pricing } \\
\text { policies for } \\
\text { devices in Europe } \\
\text { and the United } \\
\text { States should } \\
\text { encourage } \\
\text { greater value }\end{array}$ & $\begin{array}{l}\text { Sorenson } \\
\text { C, et al. }\end{array}$ & 2013 & $\begin{array}{l}\text { Revisão } \\
\text { Narrativa }\end{array}$ & $\begin{array}{l}\text { Estados } \\
\text { Unidos }\end{array}$ & $\begin{array}{l}\text { O gasto com saúde nos Estados } \\
\text { Unidos é considerado um dos } \\
\text { mais altos do mundo. } \\
\text { Comparando a Europa com os } \\
\text { Estados Unidos, a Europa } \\
\text { considera a questão de valor } \\
\text { dos dispositivos médicos para } \\
\text { determinar a cobertura de } \\
\text { reembolso, diferente dos } \\
\text { Estados Unidos. Ambos os } \\
\text { países introduziram políticas } \\
\text { para fornecer cobertura } \\
\text { temporária e reembolso de } \\
\text { tecnologias inovadoras que } \\
\text { ainda estão em fase de } \\
\text { evidência de eficácia. Sugerem } \\
\text { que sejam revistas às políticas } \\
\text { de reembolso e precificação de } \\
\text { todos os dispositivos médicos, } \\
\text { gerando melhores evidências } \\
\text { de pré e pós-mercado; também } \\
\text { sugerem que sejam } \\
\text { desenvolvidos novos métodos } \\
\text { para avaliar valor e evidência. }\end{array}$ \\
\hline 13 & $\begin{array}{l}\text { Perspective: The } \\
\text { consequence of } \\
\text { secret prices: The } \\
\text { politics of } \\
\text { physician } \\
\text { preference items }\end{array}$ & $\begin{array}{l}\text { Lerner JC, } \\
\quad \text { et al. }\end{array}$ & 2008 & $\begin{array}{l}\text { Revisão } \\
\text { Narrativa }\end{array}$ & $\begin{array}{l}\text { Estados } \\
\text { Unidos }\end{array}$ & $\begin{array}{c}\text { As cláusulas de } \\
\text { confidencialidade de preços } \\
\text { impostas aos hospitais pelos } \\
\text { fabricantes dificultam a } \\
\text { negociação dos preços Além } \\
\text { das indicações especificas que } \\
\text { o médico exige para comprar. } \\
\text { Essas decisões resultam em } \\
\text { assimetria de informação. }\end{array}$ \\
\hline 14 & $\begin{array}{l}\text { Aquisição e } \\
\text { utilização das }\end{array}$ & $\begin{array}{l}\text { Alencar } \\
\text { ACF }\end{array}$ & 2016 & $\begin{array}{l}\text { Revisão de } \\
\text { Literatura }\end{array}$ & Brasil & $\begin{array}{l}\text { Existem facilitadores de } \\
\text { superfaturamento no sistema }\end{array}$ \\
\hline
\end{tabular}


ISSN 2179-6750

\begin{tabular}{|c|c|c|c|c|c|c|}
\hline N. & Título do artigo & Autor & Ano & $\begin{array}{l}\text { Tipo de } \\
\text { Estudo }\end{array}$ & País & Principais Resultados \\
\hline & $\begin{array}{c}\text { órteses, próteses } \\
\text { e materiais } \\
\text { especiais-OPME e } \\
\text { os facilitadores } \\
\text { do } \\
\text { superfaturamento } \\
\text { no sistema de } \\
\text { saúde. }\end{array}$ & & & $\begin{array}{c}\text { não } \\
\text { sistematizada }\end{array}$ & & $\begin{array}{l}\text { de saúde, sendo estes: recursos } \\
\text { médicos abusivos, visando } \\
\text { apenas lucro, disparidade de } \\
\text { preços e denúncias veiculada } \\
\text { na mídia. Necessário há } \\
\text { regulação e a punição de } \\
\text { indivíduos ou grupos } \\
\text { fraudulentos, bem como } \\
\text { reformulação na educação de } \\
\text { cidadãos íntegros. }\end{array}$ \\
\hline 15 & $\begin{array}{l}\text { Tendências na } \\
\text { indústria } \\
\text { farmacêutica (if) } \\
\text { global: } \\
\text { dispositivos } \\
\text { médicos - } \\
\text { mercado global e } \\
\text { aspetos } \\
\text { regulamentares }\end{array}$ & Freitas JFH & 2016 & $\begin{array}{l}\text { Revisão de } \\
\text { Literatura } \\
\text { não } \\
\text { sistematizada }\end{array}$ & Portugal & $\begin{array}{l}\text { Na presente dissertação serão } \\
\text { abordados os mercados e os } \\
\text { aspectos regulamentares atuais } \\
\text { a nível global, referentes aos } \\
\text { dispositivos médicos assim } \\
\text { como tendências e possíveis } \\
\text { alterações futuras. }\end{array}$ \\
\hline 16 & $\begin{array}{l}\text { A cadeia de } \\
\quad \text { saúde } \\
\text { suplementar no } \\
\text { Brasil: avaliação } \\
\text { de falhas de } \\
\text { mercado e } \\
\text { propostas de } \\
\text { políticas }\end{array}$ & $\begin{array}{l}\text { Azevedo } \\
\text { PF, et al. }\end{array}$ & 2016 & $\begin{array}{l}\text { Pesquisa } \\
\text { Exploratória }\end{array}$ & Brasil & $\begin{array}{l}\text { A abordagem foca na saúde } \\
\text { suplementar, evidenciando } \\
\text { diversas falhas de mercado que } \\
\text { favorecem que os preços sejam } \\
\text { ineficientes. As falhas } \\
\text { apontadas: assimetria de } \\
\text { informação, poder de mercado } \\
\text { (aumentar ou diminuir preços } \\
\text { sem sofrer consequências), } \\
\text { relação financeira envolvendo } \\
\text { médicos, riscos ao paciente } \\
\text { com excessiva indicação de } \\
\text { procedimentos de alta } \\
\text { complexidade, a priorização por } \\
\text { equipamentos com maior } \\
\text { margem de lucro sem } \\
\text { apresentar efetivamente } \\
\text { melhoras ao paciente e } \\
\text { judicialização. }\end{array}$ \\
\hline 17 & $\begin{array}{c}\text { Grupo de } \\
\text { Trabalho } \\
\text { Interinstitucional } \\
\text { sobre órteses, } \\
\text { próteses e } \\
\text { materiais }\end{array}$ & $\begin{array}{c}\text { Brasil. } \\
\text { Presidência } \\
\text { da } \\
\text { República }\end{array}$ & 2015 & Relatório & Brasil & $\begin{array}{l}\text { Foi elaborado um diagnóstico } \\
\text { sobre o setor de dispositivos } \\
\text { médicos implantáveis no país, } \\
\text { propondo medidas para a sua } \\
\text { reestruturação, para correção } \\
\text { de disfunção de mercado e }\end{array}$ \\
\hline
\end{tabular}


ISSN 2179-6750

\begin{tabular}{|c|c|c|c|c|c|c|}
\hline N. & Título do artigo & Autor & Ano & $\begin{array}{l}\text { Tipo de } \\
\text { Estudo }\end{array}$ & País & Principais Resultados \\
\hline & $\begin{array}{c}\text { especiais (GTI- } \\
\text { OPME) }\end{array}$ & & & & & $\begin{array}{l}\text { condutas irregulares de } \\
\text { profissionais, transparência no } \\
\text { processo de produção, } \\
\text { importação, aquisição, } \\
\text { tributação, avaliação e } \\
\text { incorporação de tecnologia, } \\
\text { regulação de preços e } \\
\text { aprimoramento da regulação } \\
\text { clínica de acesso dos } \\
\text { dispositivos médicos em todo o } \\
\text { país. Medidas também como à } \\
\text { publicação da Portaria SAS/MS } \\
\text { n. 403, de } 7 \text { de maio de 2015, } \\
\text { que disciplinou a aquisição, o } \\
\text { recebimento, a utilização e o } \\
\text { controle de OPME pelas } \\
\text { unidades hospitalares } \\
\text { subordinadas à Secretaria de } \\
\text { Atenção à Saúde do Ministério } \\
\text { da Saúde - SAS/MS, buscando } \\
\text { regulamentar planejamento, } \\
\text { contratação e utilização de } \\
\text { OPME (decorrência do } \\
\text { escândalo máfia das próteses). } \\
\text { A lei de criação da ANS (Lei n. } \\
\text { 9.961, de 2000) dispõe em seu } \\
\text { artigo } 4{ }^{\circ} \text {, que dispõe de criar } \\
\text { medidas regulatórias de } \\
\text { avaliação e incorporação de } \\
\text { tecnologia; regulação das } \\
\text { garantias de acesso, } \\
\text { manutenção e qualidade dos } \\
\text { serviços prestados pela saúde } \\
\text { suplementar e organização do } \\
\text { sistema de informação. }\end{array}$ \\
\hline 18 & $\begin{array}{l}\text { Relatório de } \\
\text { Experiências } \\
\text { Internacionais } \\
\text { sobre Regulação } \\
\text { de Dispositivos } \\
\text { Médicos - } \\
\text { Contribuições } \\
\text { para a revisão } \\
\text { normativa da }\end{array}$ & $\begin{array}{c}\text { Brasil. } \\
\text { Presidência } \\
\text { da } \\
\text { República }\end{array}$ & 2018 & $\begin{array}{c}\text { Revisão de } \\
\text { Literatura } \\
\text { não } \\
\text { sistematizada }\end{array}$ & Brasil & $\begin{array}{l}\text { Identificam tratativas de opções } \\
\text { de regulação e/ou não } \\
\text { regulatória de dispositivos } \\
\text { médicos dos países Estados } \\
\text { Unidos, Japão, Franca e } \\
\text { Portugal para subsidiar opções } \\
\text { de regulação do Brasil. A } \\
\text { incorporação das opções de } \\
\text { outros países precisa levar em }\end{array}$ \\
\hline
\end{tabular}


ISSN 2179-6750

\begin{tabular}{|c|c|c|c|c|c|c|}
\hline N. & Título do artigo & Autor & Ano & $\begin{array}{l}\text { Tipo de } \\
\text { Estudo }\end{array}$ & País & Principais Resultados \\
\hline & RDC n. 185/2006 & & & & & $\begin{array}{c}\text { consideração as peculiaridades } \\
\text { nacionais. }\end{array}$ \\
\hline 19 & $\begin{array}{l}\text { Relatório final do } \\
\text { grupo de } \\
\text { trabalho externo } \\
\text { de órteses, } \\
\text { próteses e } \\
\text { materiais } \\
\text { especiais. (GTE } \\
\text { OPME) } \\
\text { ANS/ANVISA }\end{array}$ & $\begin{array}{c}\text { Brasil. } \\
\text { Presidência } \\
\text { da } \\
\text { República }\end{array}$ & 2016 & Relatório & Brasil & $\begin{array}{l}\text { Em atenção à referida } \\
\text { recomendação de número } 121 \\
\text { do GTI OPME, a ANS criou um } \\
\text { Grupo de Trabalho Externo } \\
\text { sobre órteses, próteses e } \\
\text { materiais especiais por meio da } \\
\text { Portaria DIDES n. 6, de } 29 \text { de } \\
\text { outubro de 2015, modificada } \\
\text { pelas Portarias DIDES n. 7, de } 5 \\
\text { de novembro de } 2015 \text {. Por } \\
\text { meio da Portaria DIDES n. 1, de } \\
26 \text { de fevereiro de } 2016, \text { que } \\
\text { revogou as anteriores, foi } \\
\text { definida a coordenação em } \\
\text { parceria pela Diretoria Adjunta } \\
\text { de Desenvolvimento Setorial da } \\
\text { ANS e Agência Nacional de } \\
\text { Vigilância Sanitária - ANVISA, } \\
\text { com a finalidade de realizar o } \\
\text { acompanhamento e o } \\
\text { gerenciamento da } \\
\text { implementação do conjunto de } \\
\text { propostas definidas no } \\
\text { Relatório Final do GTI-OPME no } \\
\text { âmbito de competência das } \\
\text { respectivas agências } \\
\text { reguladoras. }\end{array}$ \\
\hline 20 & $\begin{array}{l}\text { Relatório de } \\
\text { Definição e } \\
\text { Análise do } \\
\text { Problema } \\
\text { Regulatório1, } 2 \\
\text { Contribuições } \\
\text { para a revisão } \\
\text { normativa da } \\
\text { RDC n. 185/2006 }\end{array}$ & $\begin{array}{c}\text { Brasil. } \\
\text { Presidência } \\
\text { da } \\
\text { República }\end{array}$ & 2018 & $\begin{array}{l}\text { Revisão } \\
\text { Normativa }\end{array}$ & Brasil & $\begin{array}{l}\text { Trata-se da revisão da RDC n. } \\
\text { 185, de } 13 \text { de outubro de 2006, } \\
\text { que regulamenta o envio de } \\
\text { informações econômicas sobre } \\
\text { dispositivos médicos à ANVISA. } \\
\text { Previsto na Agenda Regulatória } \\
\text { 2017-2020. A iniciativa é da } \\
\text { elaboração de um processo de } \\
\text { Análise de Impacto Regulatório } \\
\text { (AIR). São apontadas: a) } \\
\text { irregularidades de agentes } \\
\text { econômicos b. Deficiência na } \\
\text { fiscalização, monitoramento e } \\
\text { controle sanitário c. Fatores } \\
\text { culturais d. Diversidade de }\end{array}$ \\
\hline
\end{tabular}


ISSN 2179-6750

\begin{tabular}{|c|c|c|c|c|c|c|}
\hline N. & Título do artigo & Autor & Ano & $\begin{array}{l}\text { Tipo de } \\
\text { Estudo }\end{array}$ & País & Principais Resultados \\
\hline & & & & & & $\begin{array}{l}\text { produtos (incluído, diferentes } \\
\text { termos, descrição e modelos) } \\
\text { no mercado brasileiro e. } \\
\text { Desincentivos dos fabricantes } \\
\text { em divulgar informações sobre } \\
\text { os atributos de qualidade dos } \\
\text { seus produtos f. Assimetria de } \\
\text { informação g. Existência de } \\
\text { barreiras à entrada de novas } \\
\text { empresas h. Formação de } \\
\text { monopólio/oligopólio em } \\
\text { determinados nichos de } \\
\text { mercado i Presença de } \\
\text { consumidor substituto. A } \\
\text { regulação de mercado de } \\
\text { dispositivos médicos é } \\
\text { justificada, pois precisa } \\
\text { equilibrar as falhas de mercado, } \\
\text { principalmente pela assimetria } \\
\text { de informação. Embora não } \\
\text { foram abordados neste } \\
\text { relatório, citam a necessidade } \\
\text { de reflexão no processo de } \\
\text { identificação das opções } \\
\text { regulatórias. }\end{array}$ \\
\hline 21 & $\begin{array}{l}\text { Compêndio da } \\
\text { Legislação } \\
\text { Sanitária de } \\
\text { Dispositivos } \\
\text { Médicos }\end{array}$ & $\begin{array}{c}\text { Brasil. } \\
\text { Presidência } \\
\text { da } \\
\text { República }\end{array}$ & 2001 & Compêndio & Brasil & $\begin{array}{l}\text { A publicação deste Compêndio } \\
\text { se propõe divulgar, facilitar e } \\
\text { ampliar o conhecimento dos } \\
\text { diferentes segmentos da } \\
\text { sociedade, envolvidos com a } \\
\text { área de produtos para a saúde, } \\
\text { com relação as suas regras, } \\
\text { normas e bases legais. }\end{array}$ \\
\hline
\end{tabular}

Fonte: Elaborado pelos autores (2019).

Os anos de publicação variaram de 2001 a 2019, sendo 5\% de 2001, 2003, 2012, 2013, 2015, 2017 e 2019 ( $n=1)$, 14\% de 2014 e $2018(n=3)$ e 19\% de 2008 e 2016. Os artigos focaram na questão de imperfeição do mercado de dispositivos médicos; relataram as questões sobre as regulações de dispositivos médicos; abordaram sobre a legislação e transparência de custo-efetividade dos dispositivos médicos; bem como retrataram a transparência de preços de dispositivos médicos. Em apenas 2 dos artigos houve algum 
tipo de argumento desfavorável à regulação de precificação de dispositivos médicos, sendo os demais favoráveis.

\section{Discussão}

Dispositivos médicos podem ser definidos, legalmente, como produtos voltados para a saúde, que se destinam à prevenção, diagnóstico, tratamento, reabilitação ou anticoncepção. Vale dizer que não se utilizam meio farmacológico, imunológico ou metabólico para realizar a função em seres humanos. Entretanto, contribuem como meios auxiliares. $^{2-4}$

Há uma enorme diversidade de dispositivos médicos disponíveis para os profissionais da saúde, usuários dos sistemas de saúde e instituições de saúde que podem variar desde produtos como luvas para procedimentos clinico-laboratoriais, como maquinários e softwares com tecnologias altamente sofisticadas. ${ }^{3}$ Diante de tamanha diversidade desses dispositivos médicos, torna-se complexa a regulação deles pelos gestores governamentais.

O principal objetivo de regulamentar os dispositivos médicos é permitir acesso a população a dispositivos eficazes e de alta qualidade, limitar o acesso a produtos de saúde considerados inseguros no uso da clínica, assegurando benefícios para a saúde pública. ${ }^{1}$ Entretanto, não raro ocorrem falhas nos processos regulatórios. Logo, faz-se necessário identificar as causas e agir sobre elas e suas consequências, com a finalidade de minimizar os problemas regulatórios. ${ }^{3}$

O Relatório de definição e análise do problema regulatório, ${ }^{3}$ listou algumas das falhas mais relevantes que acometem o mercado de dispositivos médicos, são elas: presença de monopólio e oligopólio; assimetria de informações; externalidades negativas (conceito que se refere aos efeitos de custos/ônus de uma atividade econômica sentida por terceiros, que não estão diretamente ligados a tal atividade) e separação das decisões de uso, de consumo e de financiamento.

Nessa perspectiva, os efeitos imediatos e secundários potencialmente provocados por essa disfuncionalidade do mercado de produtos de saúde são percebidos por preços elevados e desproporcionais nas diferentes regiões do país, dificuldade de acesso aos produtos, aumento dos custos para o sistema de saúde, judicialização da saúde, encarecimento dos planos de saúde, aumento da corrupção e da negociação pessoal nas estruturas institucionais do Brasil, procedimentos clínico-laboratoriais desnecessários e aumento de risco sanitário devido ao comportamento oportunista. ${ }^{3}$

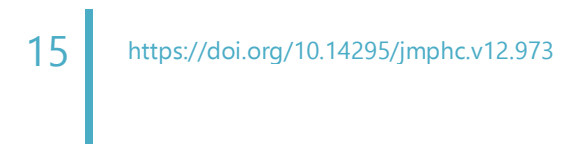


Um dos desafios a ser enfrentado, sem dúvida, remete a assimetria de informações na cadeia produtiva de dispositivos médicos. Isso porque entre os atores do setor são beneficiados aqueles que dominam o conhecimento específico sobre o produto, consequentemente favorece práticas não convencionais para obtenção de vantagens no mercado de dispositivos médicos. Em algumas regiões brasileiras ocorrem também práticas anticoncorrenciais e atitudes antiéticas e ilegais no setor. Tais práticas interferem para variações de preço desleais. ${ }^{2}$ Consequência esta que dialoga com as informações do relatório supracitado.

As falhas na regulação de mercado também podem ser observadas em outros países. Na Europa, por exemplo, pode-se argumentar que as diferenças dos regulamentos podem resultar em efeitos indesejáveis para os cidadãos. Isso porque os governos europeus atuam como compradores e reguladores dos serviços de saúde. Logo, eles podem ser tentados a usar a regulamentação como um instrumento para controlar os gastos com saúde. Nesse contexto, a regulamentação da avaliação econômica pode haver um controle de custos disfarçado. Outra situação seria o regulamento ser usado ineficientemente para mudar os custos de avaliação para fabricantes, ficando distante dos orçamentos públicos destinados para a saúde. ${ }^{6}$

O caminho apontado para enfrentar essas falhas foi a transparência e responsabilidade na forma como os compradores usam dados econômicos e para melhorar a validade e relevância dos dados econômicos fornecidos pelos fabricantes. Apostar na transparência e responsabilidade no uso da relação custo-benefício entre compradores, fornecedores e produtos de saúde contribui para favorecer todos os envolvidos deste processo. ${ }^{6}$

A elaboração de protocolos e normas relacionadas ao uso de dispositivos médicos é um aspecto que pode evitar fraudes, uma vez que visa o uso racional dos produtos de saúde e a segurança do usuário do serviço prestado. Esses protocolos atuariam para facilitar auditorias, se necessário, bem como para diminuir risco de solicitação de procedimentos desnecessários. ${ }^{7}$

Nos Estados Unidos da América - EUA foi adotada a "Lei Sunshine" como medida de transparência às relações do processo produtivo da saúde. Essa lei foi promulgada para resolver conflitos financeiros desse campo. Foi a primeira legislação federal abrangente que exigiu relatórios públicos de pagamentos entre empresas farmacêuticas, fabricantes de dispositivos e medicamentos. Essa lei é atravessada por desafios de implementação, 
que perpassa por variações consideráveis de transparência nos diferentes estágios da cadeia da saúde. ${ }^{8,9}$

Na Europa por sua vez, a nova lei da União Europeia sobre dispositivos médicos estabelece que o fabricante deve preparar um resumo de evidências para qualquer dispositivo implantável ou de alto risco. Segundo o ponto de vista clínico, as evidências revisadas pelos organismos notificados e pelas autoridades devem ser divulgadas, exceto, se justificado, as especificações técnicas consideradas confidenciais ou detalhes de fabricação protegidos como propriedade intelectual. Sob a perspectiva ética, não há razões para os profissionais de saúde terem restrições as evidências clínicas disponíveis sobre os dispositivos médicos para contribuir com suas tomadas de decisões. ${ }^{10}$

No Brasil, a regulação dos dispositivos médicos deve cumprir com a legislação da ANVISA, ${ }^{11}$ cujos produtos devem respeitar a Resolução da Diretoria Colegiada - RDC n. 185, de 2001. Este documento descreve que os dispositivos médicos devem ser descritos detalhadamente com indicação, finalidade ou uso a que se destina; precauções, restrições e advertências relacionadas ao uso; formas de apresentação; detalhamento do processo fabril com destaque para etapas críticas que comprovem o domínio tecnológico da produção, bem como contribuindo para a eficácia e segurança. Compreende-se que, mediante a transparência desse processo, é possível minimizar as chances de abusos de preços e práticas ilegais. $^{2}$

Entretanto, os mecanismos de regulação do mercado de dispositivos médicos têm se revelado insuficientes para corrigir as falhas de mercado existentes. Há ainda, por outro lado, a percepção de que a regulação por controle de preços pode gerar efeitos adversos ao mercado. Isso ocorre em particular, porque a estrutura de incentivos induz a desperdícios, excessos de procedimentos e incorporação de tecnologia que não atende a critérios de custo-eficácia. Além disso, algumas condutas podem comprometer a qualidade dos tratamentos, elevando o risco para a saúde e piorando a qualidade, como ocorre, por exemplo, quando agentes responsáveis optam por procedimentos invasivos sem necessidade, motivado apenas por ganhos financeiros. Quando situações assim acontecem, os sistemas de saúde se apresentam com um custo cada vez mais caro, porém sem oferecer qualidade. ${ }^{12}$

Problemas relacionados com o financiamento da saúde e qualidade dos serviços de saúde são estruturais, complexos, contudo demonstram ter se agravado nos últimos anos. $^{12}$ Vale ressaltar que as altas despesas com a assistência em saúde estão atreladas a um aumento da incorporação de dispositivos médicos. ${ }^{1}$

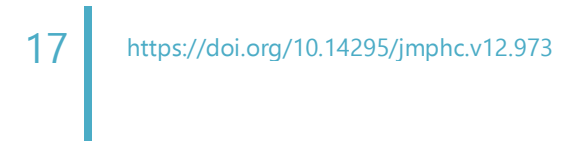


O recrudescimento dos custos com a saúde é uma preocupação internacional. Sendo uma pauta fundamental os investimentos feitos em inovações tecnológicas. Os gastos com a assistência em saúde nos EUA já ultrapassaram o montante de outros países industrializados. Por essa razão, EUA e Europa têm adotado práticas baseadas em evidências cientificas que comprovem o custo-eficácia das novas tecnologias para informar cobertura, reembolso e decisões de preços. Embora sejam estratégias que tenham sido incorporadas em países industrializados, são necessários novos estudos para comprovar sua eficácia na saúde. ${ }^{13-15}$ Ainda mais no Brasil, que apresenta um sistema de saúde peculiar em uma sociedade subdesenvolvida.

Em ambientes hospitalares, as negociações para melhorar a assistência com inovações tecnológicas é ainda mais presente. Sendo assim, os médicos, especialmente, assumem um papel sobre as escolhas dos dispositivos que almejam trabalhar. Logo, a divulgação dos preços dos dispositivos tende a ser confidencial, favorecendo assimetrias de informações entre compradores e vendedores. Nesse sentido, a legislação media essas relações para haver um custo-benefício entre as partes, propondo transparência. Por se tratar de um assunto polêmico, houve divergências nesse quesito - os estudos que são favoráveis a essa divulgação de valores e os contrários. ${ }^{16-20}$

A partir do momento que são identificados as oportunidades e os desafios envolvidos na análise econômica da estrutura de mercado dos setores de dispositivos médicos e na avaliação econômica de dispositivos médicos, pode-se ter uma ideia do quanto o mercado desses dispositivos é fragmentado e sofre com a falta de concorrência e transparência. Em resposta a isso, há ampla intervenção governamental em muitos países desenvolvidos, com o objetivo de reduzir os preços, restringir o reembolso público e promover o uso eficiente de dispositivos médicos. Contudo, são necessários estudos para avaliar e comparar as abordagens dos países no sentido de regular o mercado de dispositivos médicos, com o objetivo de informar as políticas de dispositivos médicos. Além de ser necessário realizar avaliações econômicas de dispositivos médicos com o objetivo de demonstrar sua relação custo-benefício. Portanto, os países precisam implementar estruturas para a avaliação de dispositivos médicos novos e emergentes, com o objetivo de tomar decisões sobre preços e reembolsos. ${ }^{21}$

Por fim, é válido compreender que as experiências internacionais constituem um marco referencial, especialmente para identificar e comparar opções regulatório e/ou não regulatórias, visando a melhoria da qualidade regulatória no mercado de dispositivos 
médicos. Porém, a incorporação dessas opções deve ser feita, considerando as características nacionais. $^{22}$

\section{Conclusão}

O crescente uso de dispositivos médicos no campo da saúde tem impactado diretamente no setor de administração de recursos públicos da área. Por essa questão não ser uma realidade apenas do Brasil, essa revisão colaborou para ampliar o conhecimento sobre o tema, compreendendo seus benefícios para a melhoria das condições de vida das pessoas, mas também avaliando os atravessamentos que estão ocultos na incorporação desses equipamentos pelo mercado.

Uma das dificuldades atribuídas pelos gestores no manejo desses dispositivos, sem dúvida, reside na regulação. Existe uma variedade de equipamentos com o propósito de atender os serviços da saúde, desde os casos simples até os complexos. Diante dessa diversidade, os setores que regulam esses dispositivos podem comprometer uma grande parte dos recursos financeiros somente com o consumo dessas tecnologias, sem que os interesses estejam em benefício da maioria da população atendida. Uma das estratégias para minimizar os efeitos imediatos e secundários potencialmente provocados por essa disfuncionalidade do mercado de produtos de saúde é tratar com transparência e com responsabilidade as evidências clínicas desses dispositivos, sobretudo, a forma de contratualização entre comprador e fornecedor, com acesso aos dados econômicos. Assim, seria uma possibilidade de minimizar práticas ilegais e de preços abusivos.

Os mecanismos regulatórios têm se mostrado insuficientes para lidar com as falhas desse mercado de dispositivos médicos mundialmente. Contudo, no Brasil, os efeitos podem ser ainda mais severos comparados a países como Estados Unidos e da Europa, tendo em vista que estamos submetidos a um sistema de saúde com as características peculiares de um país subdesenvolvido, com precariedade no financiamento crônico na saúde. Portanto, compete aos pesquisadores do país se aprofundar mais sobre esse assunto, aprendendo com as experiências de outros países, mas também observando o contexto brasileiro para oferecer novas possibilidades de enfrentamento para essas falhas. Assim, a gestão, os trabalhadores da saúde e a população poderão enfrentar melhor as tomadas de decisões que requerem o mercado de dispositivos médicos. 


\section{Referências}

1. Freitas JFH. tendências na indústria farmacêutica (IF) global: dispositivos médicos - mercado global e aspectos regulamentares [dissertação]. [Almada (PT)]: Instituto Superior de Ciências da Saúde Egas Moniz; 2016. 88 p.

2. Grupo de Trabalho Interinstitucional sobre Órteses, Próteses e Materiais Especiais. Relatório Final. Brasília, DF: GTI-OPME; 2015. 701 p.

3. Agência Nacional de Vigilância Sanitária. Relatório de definição e análise do problema regulatório: contribuições para a revisão normativa da RDC n. 185/2006. Brasília, DF: ANVISA; 2018 maio. 31 p.

4. Agência Nacional de Saúde Suplementar. Relatório final do grupo de trabalho externo de órteses, próteses e materiais especiais (GTI-OPME) ANS/ANVISA Rio de Janeiro: ANS; 2016. $199 \mathrm{p}$.

5. Mendes KDS, Silveira RCCP, Galvão CM. Revisão integrativa: método de pesquisa para a incorporação de evidências na saúde e na enfermagem. Texto Contexto Enferm. 2008;17(4):758-64. https://doi.org/10.1590/S0104-07072008000400018.

6. Cookson R, Hutton J. Regulating the economic evaluation of pharmaceuticals and medical devices: a European perspective. Health Policy. 2003;63(2):167-78. https://doi.org/10.1016/s0168-8510(02)00063-5.

7. Alencar C. Aquisição e utilização das órteses, próteses e materiais especiais - OPME e os facilitadores do superfaturamento no sistema de saúde [monografia]. [Brasília, DF]: Universidade de Brasília; 2016. 25 p.

8. Saver RS. Deciphering the Sunshine Act: transparency regulation and financial conflicts in health care. Am J Law Med. 2018 Feb;43(4):303-43. https://doi.org/10.1177/0098858817753403.

9. Hwang TJ, Avorn J, Kesselheim AS. Life cycle of medical product rules issued by the US Food and Drug Administration. J Health Politi Policy Law. 2014 Aug;39(4):751-80. https://doi.org/10.1215/03616878-2743027.

10. Fraser AG, Butchart EG, Szymański P, Caiani EG, Crosby $S$, Kearney $P$, et al. The need for transparency of clinical evidence for medical devices in Europe. Lancet. 2018 Aug;392(101146):521-30. https://doi.org/10.1016/S0140-6736(18)31270-4.

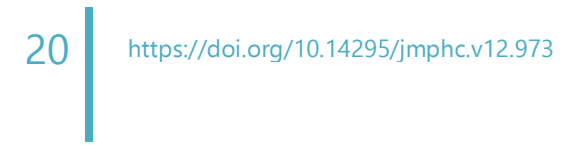


11. Agência Brasileira de Desenvolvimento Industrial. Compêndio da Legislação Sanitária de Dispositivos Médicos: versão 3.4. Brasília, DF: ABDI; 2011. 376 p.

12. Azevedo $P F$, Almeida SF, Ito NC, Boarati $V$, Moron $C R$, Inhasz W, et al. A cadeia de saúde suplementar no Brasil: avaliação de falhas de mercado e propostas de políticas. São Paulo: Insper; 2016. 123 p. (White Paper 1).

13. Sorenson C, Drummond M, Burns LR. Evolving reimbursement and pricing policies for devices in Europe and the United States should encourage greater value. Health Aff (Millwood). 2013 Apr;32(4):788-96. https://doi.org/10.1377/hlthaff.2012.1210.

14. Sorenson C, Drummond M. Improving medical device regulation: the United States and Europe in perspective. Milbank Q. 2014 Mar;92(1):114-50. https://doi.org/10.1111/14680009.12043.

15. Kramer DB, Xu S, Kesselheim A. How does medical device regulation perform in the United States and the European Union? A systematic review. PLoS Med. 2012;9(7):e1001276. https://doi.org/10.1371/journal.pmed.1001276.

16. Martelli $\mathrm{N}$, van den Brink $\mathrm{H}$. Special funding schemes for innovative medical devices in French hospitals: The pros and cons of two different approaches. Health Policy. 2014 Jul;117(1):1-5. https://doi.org/10.1016/j.healthpol.2014.04.007.

17. Camus D, Thiveaud D, Josseran A, participants of GIENS XXXIV round table "Health Technologies". New European medical device regulation: How the French ecosystem should seize the opportunity of the EUDAMED and the UDI system, while overcoming the constraints thereof. Therapie. 2019;74(1):73-85. https://doi.org/10.1016/j.therap.2018.12.001.

18. Pauly MV; Burns LR. Price transparency for medical devices. Health Aff (Millwood). 2008 Nov-Dec;27(6):1544-53. https://doi.org/10.1377/hlthaff.27.6.1544.

19. Lerner JC, Fox DM, Nelson T, Reiss JB. The consequence of secret prices: the politics of physician preference items. Health Aff (Millwood). 2008 Nov-Dec;27(6):1560-65. https://doi.org/10.1377/hlthaff.27.6.1560.

20. Hahn RW, Klovers KB, Singer HJ. The need for greater price transparency in the medical device industry: an economic analysis. Health Aff (Millwood). 2008 Nov-Dec;27(6):1554-9. https://doi.org/10.1377/hlthaff.27.6.1554.

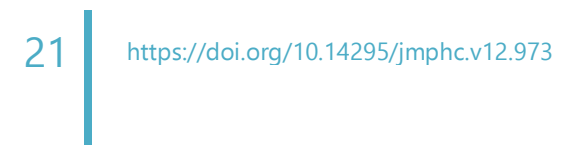


21. Simoens S. Health economics of medical devices: opportunities and challenges. J Med Econ. 2008 Dec;11(4):713-7. https://doi.org/10.3111/13696990802596721.

22. Agência Nacional de Vigilância Sanitária. Relatório de experiências internacionais sobre regulação de dispositivos médicos: contribuições para a revisão normativa da RDC $n$. 185/2006. Brasília, DF: Anvisa; 2018 jun. 44 p.

\section{Minicurrículo}

Thais Seiler | ORCiD: 0000-0002-9781-3635

Especialista em Economia e Gestão em Saúde pela Universidade de São Paulo - USP, São Paulo, SP, Brasil.

Tarsila Teixeira Vilhena Lopes | ORCiD: 0000-0002-5191-9717

Doutoranda em Saúde Pública, Universidade de São Paulo - USP, São Paulo, SP, Brasil.

Brunna Verna Castro Gondinho | ORCiD: 0000-0002-1061-4407

Professora da Faculdade de Odontologia e Enfermagem da Universidade Estadual do Piauí FACOE/UESPI. Parnaíba, PI, Brasil.

Felipe Galvão Machado | ORCiD: 0000-0003-1291-3328

Mestre em Saúde Pública, Universidade de São Paulo - USP, São Paulo, SP, Brasil.

Jaqueline Vilela Bulgarelli | ORCiD: 0000-0001-7810-0595

Professora da área de Odontologia Preventiva e Social da FOUFU - Faculdade de Odontologia da Universidade de Uberlândia, Minas Gerais, MG, Brasil. 